\title{
Performance evaluation of a DC-AC inverter controlled with ZAD-FPIC
}

\section{Evaluación del desempeño de un inversor DC-AC controlado con ZAD-FPIC}

\author{
DOI: http://dx.doi.org/10.17981/ingecuc.14.1.2018.01
}

Artículo de investigación científica. Fecha de recepción: 25/10/2017. Fecha de aceptación:11/12/2017.

\author{
F. E Hoyos \\ Universidad Nacional de Colombia - Sede Medellín. Facultad de Ciencias, Escuela de Física. Medellín (Colombia). \\ fehoyosve@unal.edu.co

\section{J. E. Candelo} \\ Universidad Nacional de Colombia - Sede Medellín, Facultad de Minas, \\ Departamento de Energía Eléctrica y Automática. Medellín (Colombia). \\ jecandelob@unal.edu.co
}

\section{J. I. Silva}

Universidad de la Costa, Departamento de Energía. Barranquilla (Colombia). Estudiante de doctorado en Ingeniería de Universidad Pontificia Bolivariana. Medellín (Colombia). jsilva6@cuc.edu.co

Para citar este artículo:

F. Hoyos, J. Candelo y J. Silva. "Performance evaluation of a DC-AC inverter controlled with ZAD-FPIC" INGE CUC, vol. 14, no. 1, pp. 9-18, 2018 DOI: http://doi.org/10.17981/ingecuc.14.1.2018.01

\begin{abstract}
Introduction- Power converters are used in microgrids to transfer power to the load with a regulated voltage. However, the DC-AC converters present distortions in the waveform that can be improved with the help of real-time controllers.
\end{abstract}

Objective- Evaluate the response in alternating current of the buck converter controlled with the ZAD-FPIC technique.

Methodology- Based on the differential equations that describe the buck power converter, the ZAD and FPIC controllers are designed. Afterwards, simulations of the complete controlled system are made using Simulink of MATLAB. Then, the system is implemented experimentally and the controller is executed in real-time with the help of a DS1104 from dSPACE. In the end, several tests are carried out to check the effectiveness of the controller.

Results- The results show that the controller allows good stability against different variations in the system and in the load.

Conclusions- The ZAD-FPIC technique controls the variable and tracks changes in the waveform, magnitude, and frequency of the reference signal. The controller presents good stability to different tests, tracking the reference signal after each event.

Keywords- Control of power converters, ZAD-FPIC technique, DC-AC converter, signal tracking

\section{Resumen}

Introducción- Los convertidores de potencia son utilizados en las micro redes para transferir la potencia a la carga con una tensión regulada. Sin embargo, los convertidores DC-AC presentan distorsiones en la forma de onda que pueden ser mejoradas con la ayuda de controladores en tiempo real.

Objetivo- Evaluar la respuesta en corriente alterna del convertidor buck controlado con la técnica ZAD-FPIC

Metodología- Se parte de las ecuaciones diferenciales que describen el convertidor de potencia buck, luego se diseñan los controladores ZAD y FPIC, se hacen simulaciones del sistema completo controlado en Simulink de Matlab, se implementa el sistema de forma experimental y el controlador se ejecuta en tiempo real con la ayuda de una DS1104 de la empresa dSPACE, al final se realizan varias pruebas para comprobar la efectividad del controlador.

Resultados- Los resultados muestran que el controlador permite que una buena estabilidad contra diversas variaciones en el sistema y en la carga.

Conclusiones- La técnica ZAD-FPIC controla la variable y realiza seguimiento ante cambios en la forma de onda, magnitud y frecuencia de la señal de referencia. El controlador presenta buena estabilidad ante diferentes pruebas, siguiendo la señal de referencia después de cada evento.

Palabras clave- Control de convertidores de potencia, técnica ZAD-FPIC, convertidor DC-AC, seguimiento de señales 


\section{INTRODUCTION}

Power converters are used to transfer electrical energy [1] in a network from direct to direct current (DC-DC) or from direct to alternating current (DC-AC), which is useful for renewable generation sources [2], [3]. This conversion can be performed to supply loads that are connected to the network, with the guarantee of security, reliability, and low cost [4]. However, different types of load are normally connected to power converters, such as electric welders, communication equipment, and electrical elements of medicine, among others [5]. This results in significant load variations [6], [7], which must be analyzed to know the best solution for the system.

The technique known as "zero average dynamics" (ZAD) has been used in previous studies [8], [9] because it allows to maintain the commutation frequency [10]. This technique is validated by analytical and numerical results while changing the parameters that determine the stability of the system [11]. Fixed point inducting control (FPIC) is also used to maintain system stability.

The previous literature has investigated how unstable orbits in the chaos can be controlled in DC power converters by using the ZAD-FPIC technique. Numerical [12], analytical [13], and experimental tests also were performed to validate the different responses of DC-DC converters [14]. However, many of these works are dedicated to show the behavior of DC-DC converters, and only a few for DC-AC converters. Studies of the latter should be done more broadly to identify the ways these converters respond to changes generated in the system. Additionally, there is no research at the numerical or experimental level where FPIC control in DC-AC conversion is used to improve system stability.

This article presents the performance of the buck converter in response in alternating current controlled by ZAD and FPIC. Variations in the controller are performed to identify responses in the output voltage and current. Controller performance is described for signal variation, using different types of tests such as waveform and frequency, among others while also considering disturbances as the load changes. In general, several tests are developed to show the robustness of the system experimentally.

The rest of the paper is divided into three sections. Section 2 presents the methodology used in this research with the electronic circuit, the control techniques, and the experimental analysis considered. Section 3 presents the results, the analysis, and discussions arising from the results. Finally, section 4 describes conclusions obtained from the prototype of the DC-AC power inverter controlled by ZAD-FPIC.

\section{Methodology}

In this section, the mathematical model of the buck converter with the ZAD-FPIC technique is presented with the calculation of the duty cycle, which is the percentage of time in which the switch is in 1 (Fig. 1). This value depends on the variables of the system, the reference, and the control parameters used in the investigation.

\section{A. DC-AC converter}

Fig. 1 presents a diagram of a DC-AC converter. The diagram shows two sources and a commutation switch, a filter with an inductor and capacitor (LC), and a resistive load (R). The initial system configuration is given to start with a non-regulated DC input voltage $E$ and a centered pulse width modulation $(\mathrm{CPWM})$ at a constant frequency $(5 \mathrm{kHz})$. The regulated output signal ( can be obtained for DC or AC depending on the reference signal, which is useful for home applications [3].

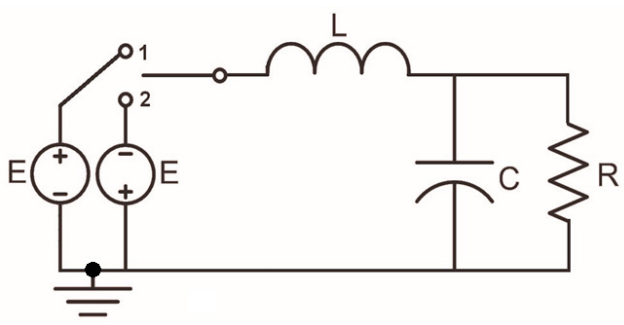

Fig. 1. DC-AC converter Source: Authors.

The switch changes position to 1 or 2 , depending on the control signal $(u)$, which controls the time that the switch is connected to the filter. During the operation, the model of the buck converter can be represented as shown in Fig. 2. This model considers the internal resistance of the inductor $r_{L}$ and it has a serial connection with the inductor $L$ and the source $E u$ as previously tested in [11] and [15]. The model considers the capacitor connected in parallel to the load $R$. The output signal can be measured by the resistance $R$ as $v_{c}=i_{R} * R$. Herein, the current flowing through the inductor is $i_{L}$ and the current in the load $i_{R}$.

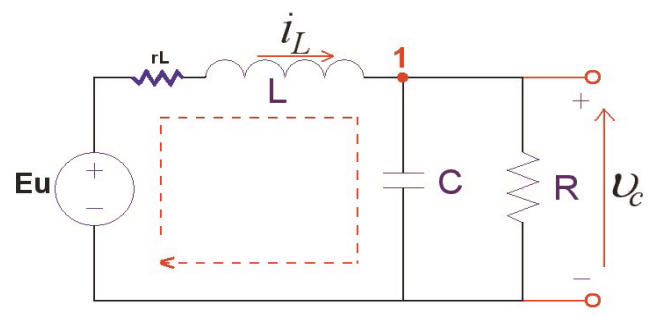

Fig. 2. Electrical circuit under study Source: Authors. 
From this circuit, the linear mathematical model in the state variables is shown in Eq. (1). Herein, $a=-1 / R C, h=1 / C, m=-1 / L$, and $p=-r / L$. The state variables are the voltage in the capacitor $\left(v_{c}\right)$ and the current through the inductor $\left(i_{L}\right)$ :

$$
\dot{v}_{C}=\left[\begin{array}{cc}
-\frac{1}{R C} & \frac{1}{C} \\
-\frac{1}{L} & -r_{L}
\end{array}\right]\left[\begin{array}{c}
v_{C} \\
i_{L}
\end{array}\right]+\left[\begin{array}{c}
0 \\
\underline{E} \\
L
\end{array}\right] u
$$

The control signal $u$ changes values between $(+1$, $-1)$ as shown in Figs. 1 and 3. With the changes in the control signal, two types of system topologies are presented for each period with the CPWM. The resulting model in the representation, $\dot{x}=A x+B u$, is shown in Eq. (2), where $\mathrm{x}=\left[x_{1}, x_{2}\right]^{\prime}=\left[v_{C}, i_{L}\right]^{\prime}$. In this equation, the term $T$ is the commutation period and the term $d$ is the duty cycle.

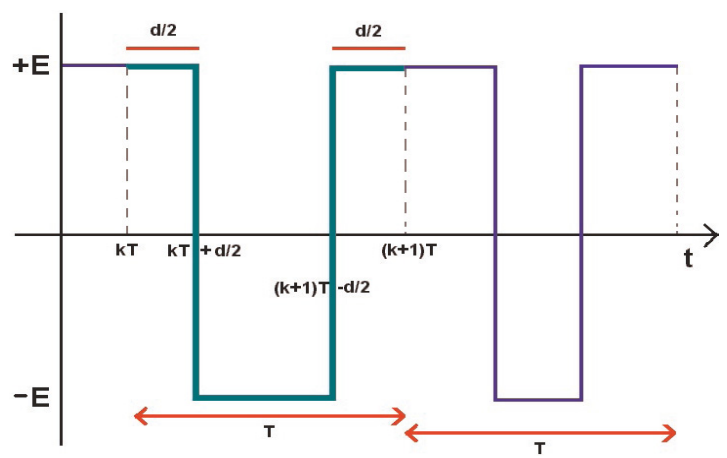

Fig. 3. Control signal + and - with CPWM Source: Authors.

$$
\dot{x}=\left\{\begin{array}{llc}
A x+B & u=+1 & 0 \leq t \leq \frac{\mathrm{d}}{2} \\
A x-B & u=-1 & \frac{d}{2} \leq t \leq T-\frac{d}{2} \\
A x+B & u=+1 & T-\frac{d}{2} \leq t \leq T
\end{array}\right.
$$

A controller can be designed by generating a duty cycle that controls both the voltage and the stability of the system. The ZAD and FPIC techniques were designed with this purpose and they will be explained in the next subsections.

\section{B. Control with ZAD}

This technique was proposed in [8], and later tested numerically and experimentally in [11], [16], and [17]. This technique basically consists of defining a function and forcing an average value of zero at each sampling period. For this particular case, $s(t)$ is used as a time domain function of the state value at the start of the sampling period $(x(k T))$.

Considering linearity in the sliding surface $s(x)$, the duty cycle is modified by the ZAD as expressed in Eq. (3):

$$
d_{z a d(k T)}=\frac{\left(2 s(x(k T))+T \dot{s}_{-}(x(k T))\right.}{\dot{s}_{-}(x(k T))-\dot{s}_{+}(x(k T))}
$$

where:

$$
\begin{aligned}
s(x(K T))= & \left(1+a K_{s}\right) x_{1}(K T)+K_{s} h x_{2}(K T)-x_{1 r e f}-K_{s} \dot{x}_{1 r e f}(4) \\
\dot{s}_{+}(x(K T))= & \left(a+a^{2} K_{s}+h K_{s} m\right) x_{1}(k T) \\
& +\left(h+a h K_{\mathrm{s}}+h K_{s} p\right) x_{2}(K T)+h K_{\mathrm{s}} \frac{E}{L} \\
& \quad-\dot{x}_{1 r e f}-K_{s} \ddot{x}_{1 r e f} \\
\dot{s}_{-}(x(K T))= & \left(a+a^{2} K_{s}+h K_{\mathrm{s}} m\right) x_{1}(k T) \\
& +\left(h+a h K_{\mathrm{s}}+h K_{s} p\right) x_{2}(K T)-h K_{\mathrm{s}} \frac{E}{L} \\
& -\dot{x}_{1 r e f}-K_{s} \ddot{x}_{1 r e f}
\end{aligned}
$$

The variables $a, h, m$, and $p$ were described before and $k_{s}$ is the parameter of the ZAD control, $\dot{x}_{1 r e f}=v_{\text {ref }}$ is the reference signal, and $\dot{x}_{1 r e f}, \ddot{x}_{1 r e f}$ are their derivatives. For more details see [18].

\section{Control with FPIC}

The FPIC technique was presented in [18] and later tested in [19] and [20]. This technique is useful for autonomous and non-autonomous systems, especially to control discrete systems. This is based on the continuity theorem of the eigenvalues and it is used to stabilize the orbits of one or more periods in unstable or chaotic systems. This technique does not require to measure the state variables. It forces the system to evolve to a fixed point; therefore, it is necessary to have prior knowledge of the equilibrium point of the control signal.

Starting from Eq. (3) with $x_{1}=x_{1 r e f}, \dot{x}_{1 r e f}$ (in the steady state), and $\dot{x}_{1}=a x_{1}+h x_{2}$, the duty cycle is calculated for the steady-state with Eq. (7):

$$
\begin{aligned}
d s s & =\frac{T\left[h K_{s} m x_{1 r e f}+a K_{s} \dot{x}_{1 r e f}+K_{s} p \dot{x}_{1 r e f}\right]}{-2 h K_{s} \frac{E}{L}} \\
& \frac{+T\left[-a K_{s} p \dot{x}_{1 r e f}-h K_{s} \frac{E}{L}-K_{s} \ddot{x}_{1 r e f}\right]}{-2 h K_{s} \frac{E}{L}}
\end{aligned}
$$

\section{Control with ZAD and FPIC}

Both the ZAD and FPIC techniques can be used to control the output voltage in the power inverter, with $\left(x_{1}=v_{c}\right)$ and $\left(x_{2}=i_{L}\right)$ as the system variables, the ZAD control parameter $K_{s}$, the FPIC parameter $N$, the reference voltage $x_{1 r e f}=v_{\text {ref }}$, and the input voltage $E$.

Using Eq. (8) with Eqs. (3)-(7), the control variable $(d)$ with ZAD and FPIC is calculated with a frequency of $\mathrm{kHz}$, to close the control loop. If the converter regulates the output voltage $v_{C}$ for variable loads, then it is necessary to update the values of the load; thus, it is useful to measure the current in the inductor $\left(x_{2}=i_{L}\right)$ and the voltage in the load $\left(x_{1}=v_{C}\right)$ : 


$$
d=\frac{d_{z a d(k T)}+N d s s}{N+1}
$$

For more information about the FPIC control technique and parameter, it is recommended to review [17]-[19].

The advantages of using the ZAD-FPIC control techniques are that they have fixed switching frequency, operate under steady-state error, and the system is more robust in the presence of chaos and oscillations. This can be evidenced in previous investigations [11], [15], and [17].

\section{E. Experimental development}

The ZAP-FPIC controller is shown in Fig. 4. The hardware design is based on analog electronic devices comprising an optoelectronic driver and MOSFETs that integrate the DC-AC inverter. The load is resistive and sensor and signal processing use operational amplifiers. The rest of the system is developed with the DSP (digital signal processor) card DS1104 produced by dSPACE, which is programmed for the following phases: signal acquisition with 12 bits with a sampling rate of $5 \mathrm{kHz}$, the controllers ZAD-FPIC implementation for the real-time control of the converters using a CPWM signal. The controllers require parameters such as $x_{1 r e f}, C, L, E, K_{s}$ and $N$; the values used in this research are presented in Table 1.

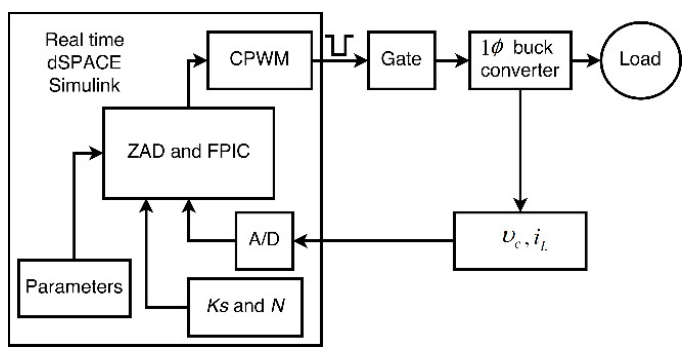

Fig. 4. Block diagram of experiment for ZAD-FPIC controllers Source: Authors.

Table 1: Parameters used in the AC test

\begin{tabular}{|c|c|c|}
\hline Parameter & Description & Value \\
\hline$R$ & Resistance of load & $151.3 \Omega$ \\
$C$ & Capacitance & $57.68 \mu \mathrm{f}$ \\
$L$ & Inductance & $3.945 \mathrm{mH}$ \\
$r_{L}$ & Internal resistance & $4 \Omega$ \\
$E$ & Input voltage & $\pm 32 \mathrm{~V}$ \\
$F_{c}$ & Commutation frequency & $5 \mathrm{kHz}$ \\
$F_{s}$ & Sampling frequency & $5 \mathrm{kHz}$ \\
$K_{s}$ & Control parameter ZAD & 5 \\
$N$ & Control parameter FPIC & 1 \\
\hline
\end{tabular}

Source: Authors.
To convert the signal from DC to AC, it is necessary to implement a half bridge. This is used to feed the LC circuit with the sources and by a CPWM as shown in Fig. 5. To avoid a short circuit on the transistors, it is necessary to use complementary control signals $+u=u=1$ and $-u=u=-1$.

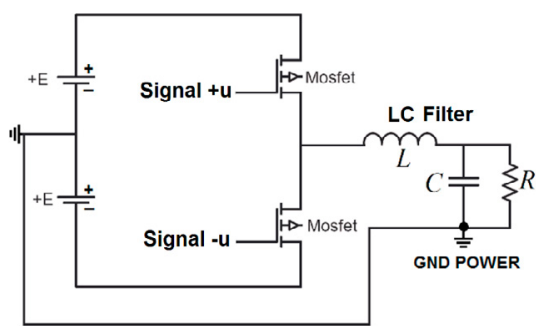

Fig. 5. Half bridge Source: Authors.

Because CPWM $(+u)$ and CPWMinv $(-u)$ outputs are obtained with the DSP and have the same ground references, it is necessary to decouple the digital circuits from the power circuits. This is the purpose of the high-speed optocoupler grid shown in Fig. 6.

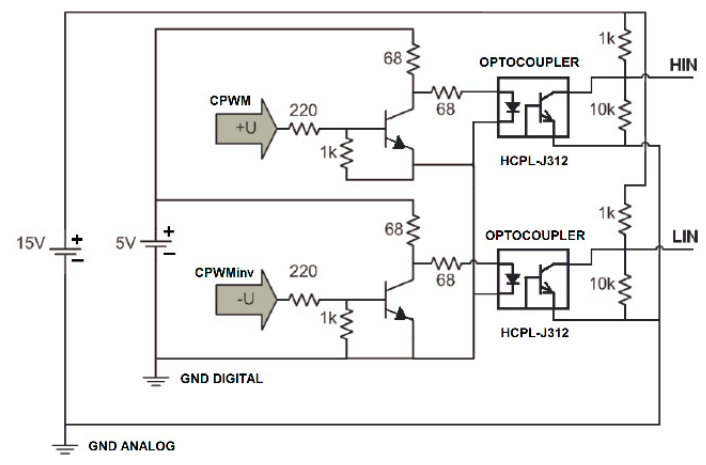

Fig. 6. Optoelectronic insulation Source: Authors.

The circuit operates as follow: the DS1104 card provides two signal, digital and complementary (CPWM and CPWMinv) as they are required to activate the MOSFETs as shown in Figs. 5 and 6. These outputs are raised to $13.5 \mathrm{~V}$ in HIN and LIN outputs related to the analogic ground system. They also are isolated from the digital ground reference, which is required to use the IR2110 as shown in Fig. 7.

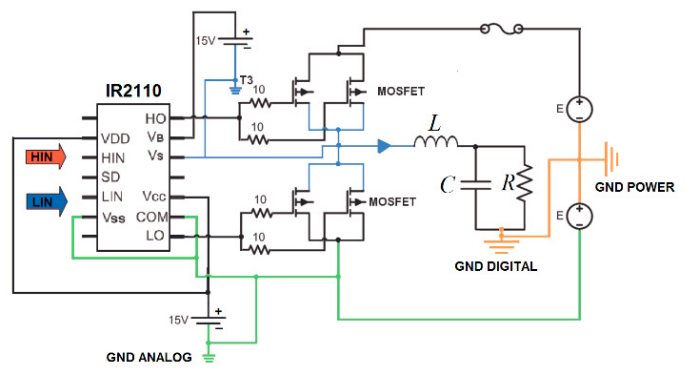

Fig. 7. MOSFET application in the DC-AC process Source: Authors. 
In Fig. 7, HIN is the output provided by the first optocoupler presented in Fig. 6. This signal is adapted through the IR2110, converting it in the output signal HO with isolated ground reference (T3). This is used to provide the ON-OFF process of the two MOSFETs that are located in the high part. The LIN output of the optocouplers from the lower part is converted to the LO output with the GND analog reference as in Fig. 7, which handles the MOSFET located in the lower part. This design can withstand up to $500 \mathrm{~V}$ and $30 \mathrm{~A}$ depending on the MOSFET used.

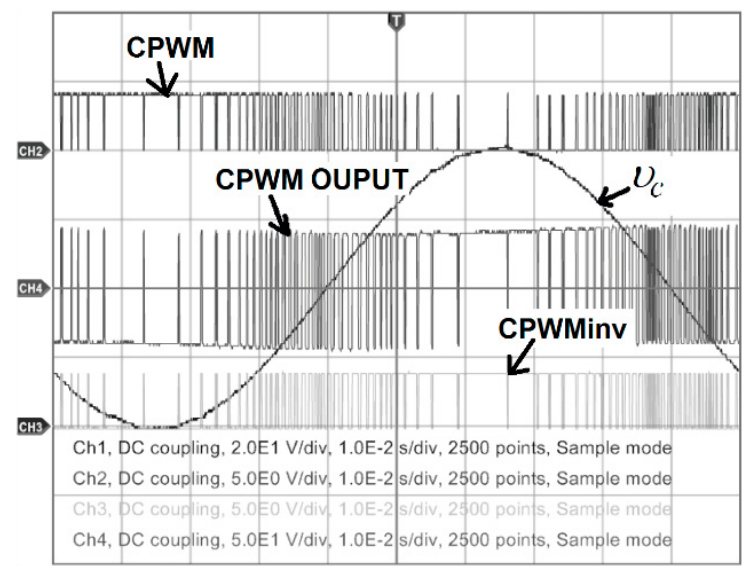

Fig. 8. Output signal obtained with the CPWM and voltage in the load after the filter Source: Authors.

Fig. 7 displays the results using the filter implemented based on the LC process. It receives highfrequency signals from the CPWM and, with the LC, converts these to AC and DC signals with regulation at the outputs. Fig. 8 shows the voltage $v_{C}$ in the capacitor and the CPWM signals obtained by the inverter.

This commuted system is likely to present electromagnetic interference (EMI) [21]. For that reason, the sensed signals $v_{C}$ and $i_{L}$ provided by the converter must be shielded as in Fig. 9.

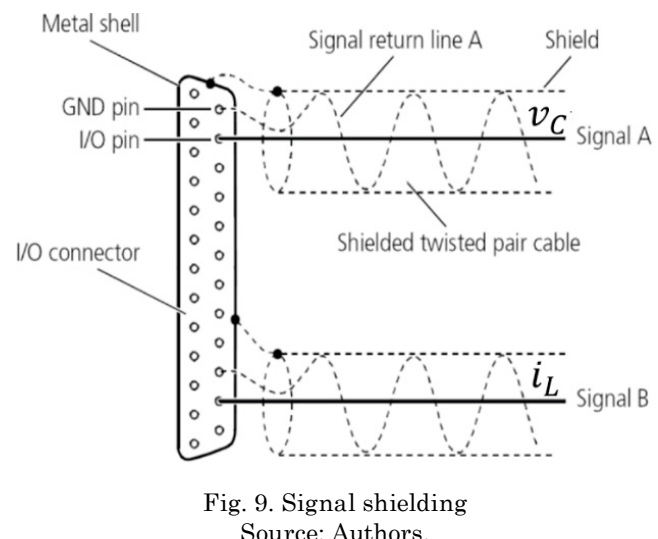

\section{Results AND ANALYsis}

This section presents the results of the control response with the signals in AC. Initially, the parameters of the controller are used in the tests to evaluate changes in the output voltage and current.

\section{A. Parameters for the test}

Table 1 shows the parameters of the implemented circuit. The converter uses the power from a dual source BK PRECISION (reference 1761) with a voltage of $\mathrm{E}=32 \mathrm{~V}$. The value of the capacitor used for the LC filter was reduced to tracking the AC signals at a higher frequency.

\section{B. Performance of the buck converter in $A C$}

Figs. 10-12 show the performance of the buck converter with the control techniques. The signals have a sinusoidal waveform $x_{1 \text { ref }}=20 * \operatorname{sen}(2 \Pi * 20 \mathrm{t}) \mathrm{V}$.

Channel 1 (CH1) shows the current in the load $i_{R}$ (lower part of the figure); as the load impedance is $151.3 \Omega$, the peak current in the same is approximately $132 \mathrm{~mA}$. This signal has a gain of $200 \mathrm{mV} /$ div. Next, channel 2 (CH2) shows the output PWM that feeds the LC filter (upper part of the figure). The voltage produced with the CPWM signal has an amplitude of $\pm 32 \mathrm{~V}$. Note that this channel has a gain of $50 \mathrm{~V} /$ div and this signal is switching at a constant frequency of $5 \mathrm{kHz}$. Finally, channel 3 (CH3) shows the output voltage $v_{C}$ with an amplitude of 20 $\mathrm{V}$ and a frequency of $20 \mathrm{~Hz}$ (middle part of the figure). This channel has a gain of $10 \mathrm{~V} /$ div.

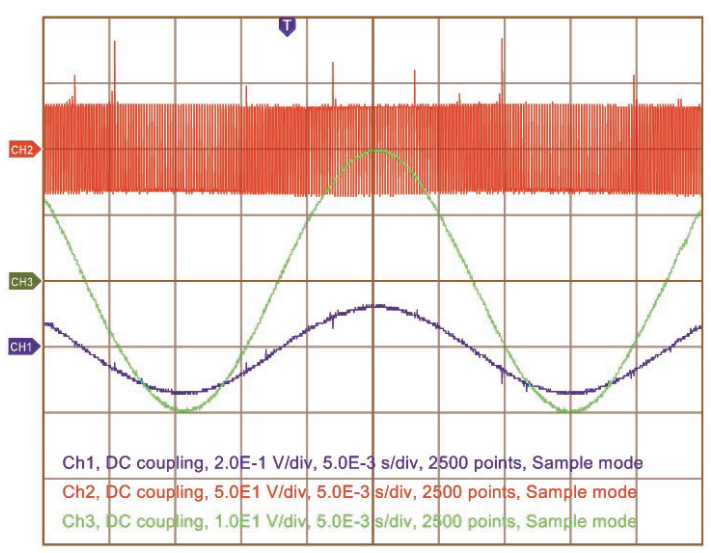

Fig. 10. PWMC, $v_{C}$, and $i_{R}$ when $x_{1 r e f}=20 * \sin (2 \pi * 20 \mathrm{t}) \mathrm{V}$ Source: Authors.

Fig. 11 shows the voltage in the capacitor $\left(v_{C}\right)$, the current in the inductor $\left(i_{L}\right)$, and the current in the load $\left(i_{R}\right)$. These signals were acquired with the program ControlDesk for the same reference signal $20 * \sin (2 \pi * 20 \mathrm{t}) \mathrm{V}$. 


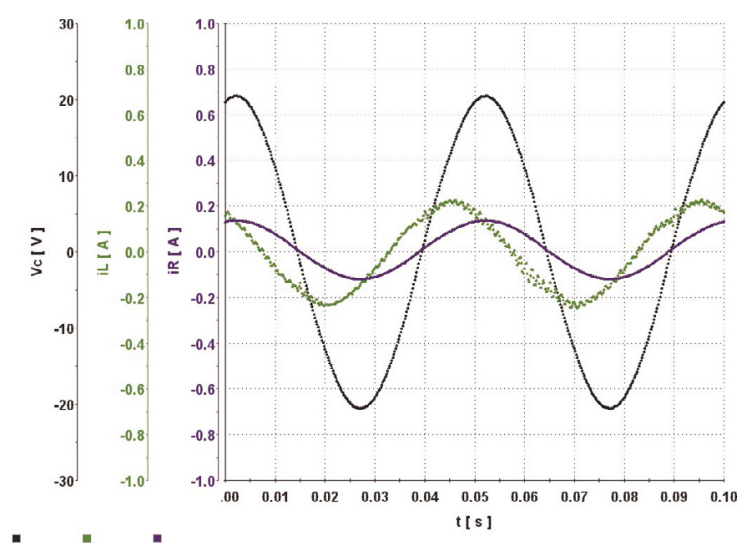

Fig. 11. $v_{C}, i_{L}$, and iR plotted in ControlDesk when $v_{\text {ref }}=20 \sin \left(2 \Pi^{*} 20 \mathrm{t}\right) \mathrm{V}$ Source: Authors.

The error in Fig. 12 is in the range of $\pm 5 \%$ because the duty cycle $(d)$ is not saturated. A fixed switching frequency is presented. The current in the inductor $\left(i_{L}\right)$ (Fig. 11) is lagged with respect to the voltage signal $\left(v_{C}\right)$. The current signal in the inductor has a large ripple due to transistor switching at $5 \mathrm{kHz}$.

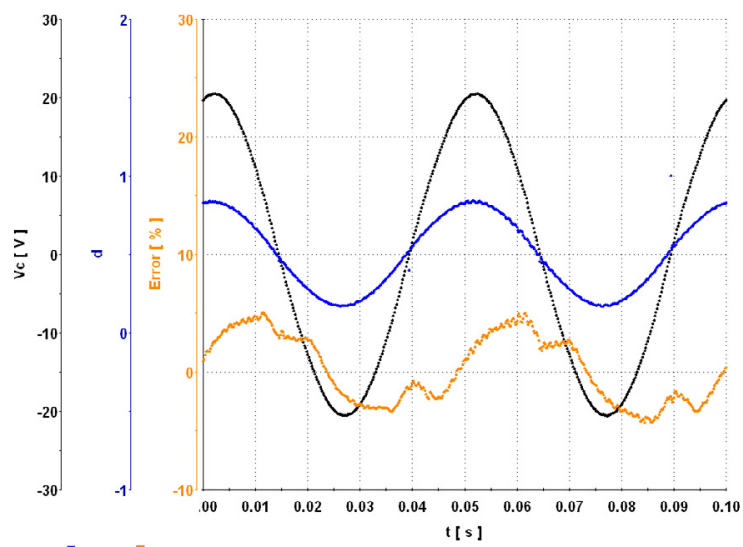

Fig. 12. $v_{C}, d$, and error plotted in ControlDesk when $v_{\text {ref }}=20 \sin (2 \pi * 20 \mathrm{t}) \mathrm{V}$ Source: Authors.

\section{1) Performance of the buck converter in AC with triangle waveform}

Fig. 13 shows the performance of the controllers when the signal to follow is a triangle waveform of amplitude $20 \mathrm{~V}$ with a frequency of $20 \mathrm{~Hz}$.

This figure shows the input feeding of the filter with the CPWM, the output voltage, and the current in the load $i_{R}$. It can be observed that the waveform changes according to the signal to be followed and the controller shows a better performance. Therefore, it is possible to control the output of any type of waveform the user requires.

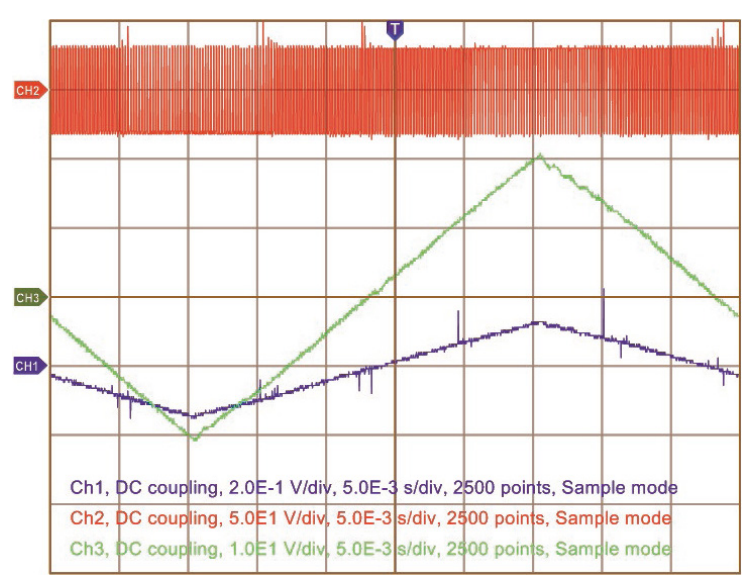

Fig. 13. PWMC, $v_{C}$, and $i_{R}$ signals when uref is a triangle waveform Source: Authors.

\section{B. Changes in the voltage reference}

Fig. 14 shows the behavior of the voltage signal with a quick change in the reference signal. The initial sinusoidal signal, with a magnitude of 20 $\mathrm{V}$ peak and frequency of $10 \mathrm{~Hz}$, changes to a new square signal with voltage magnitude peak of $20 \mathrm{~V}$ and frequency of $10 \mathrm{~Hz}$.

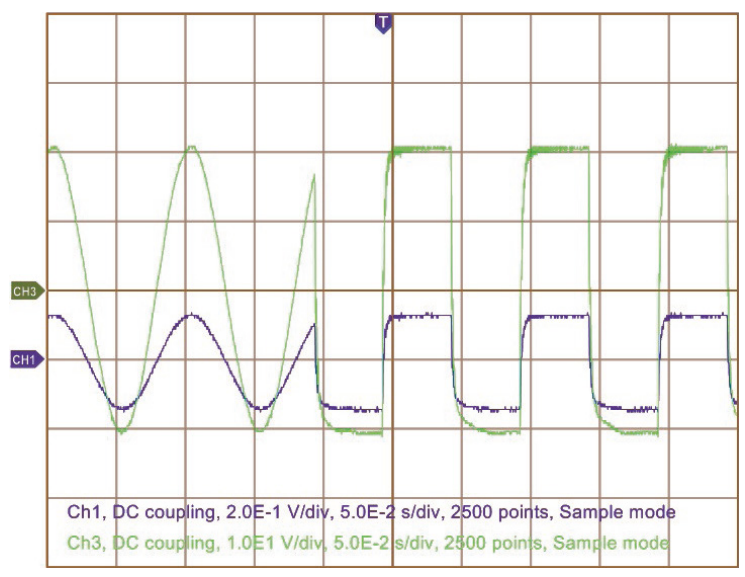

Fig. 14. Behavior of the buck converter with changes in the waveform of the reference from sinusoidal to square Source: Authors.

Fig. 15 shows the behavior of the voltage signal when a quick change in the waveform of the reference signal is performed. The reference signal changes from a triangle shape with voltage magnitude of $30 \mathrm{~V}$ and $10 \mathrm{~Hz}$ to a sinusoidal signal with the same characteristics.

Fig. 16 shows the behavior of the output voltage signal when the signal frequency is changed from $v_{\text {ref }}=25 \operatorname{sen}(2 \Pi * 10 \mathrm{t}) \mathrm{V}$ to $v_{\text {ref }}=25 \operatorname{sen}(2 \pi$ * 20t) V. 


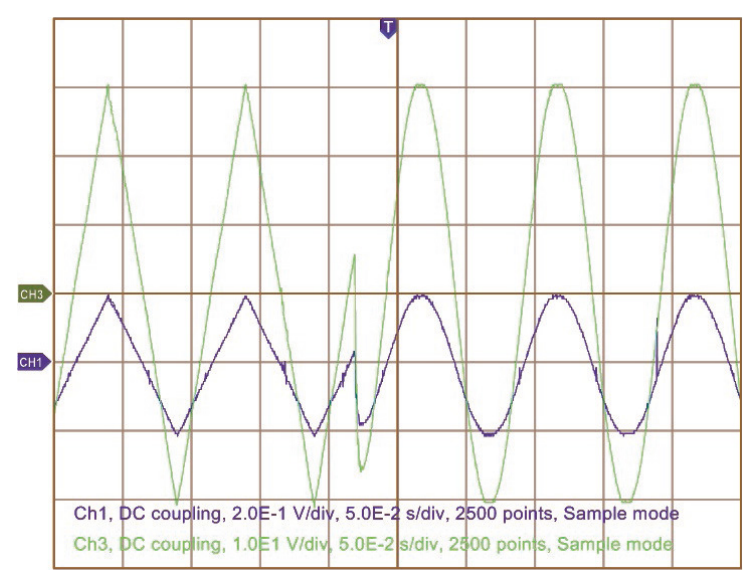

Fig. 15. Instantaneous change from triangle to sinusoidal waveform Source: Authors.

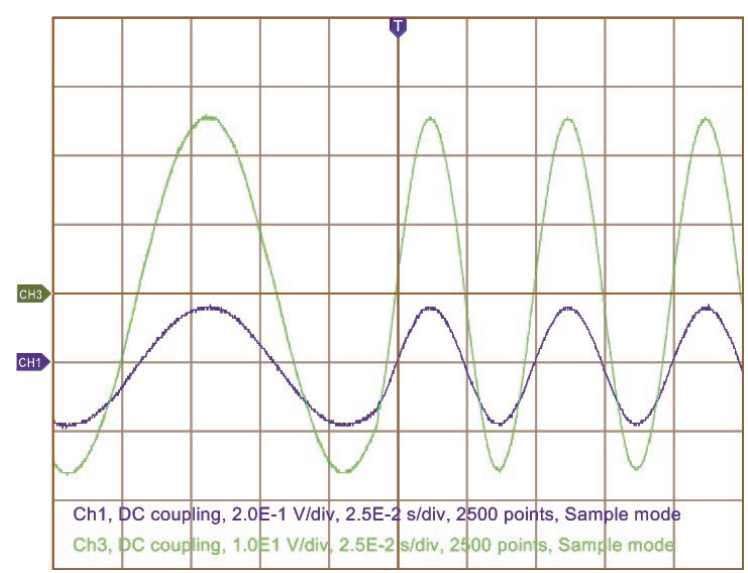

Fig. 16. Instantaneous change in the frequency from $10 \mathrm{~Hz}$ to $20 \mathrm{~Hz}$ Source: Authors.

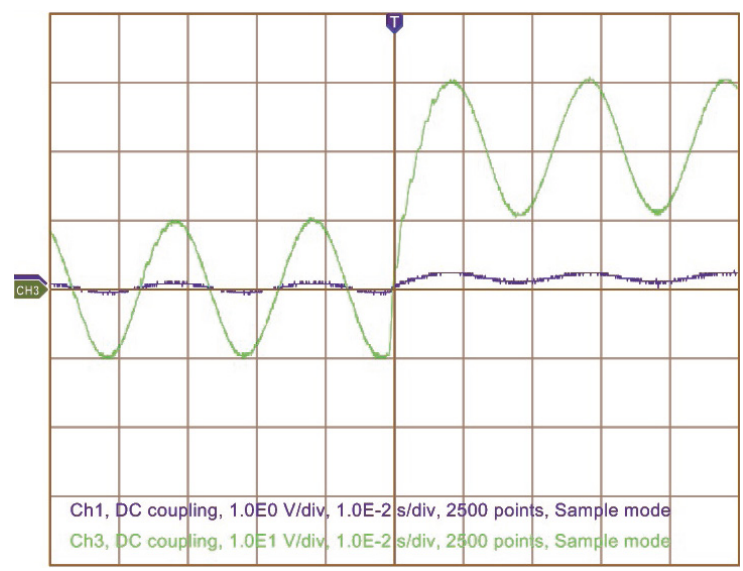

Fig. 17. Behavior of the $v c$ and $i_{R}$ when the voltage reference changes from $v_{\text {ref }}=10 \operatorname{sen}(2 \pi * 50 \mathrm{t}) \mathrm{V}$ to $v_{\text {ref }}=20+10 \operatorname{sen}(2 \pi * 50 \mathrm{t}) \mathrm{V}$ Source: Authors.

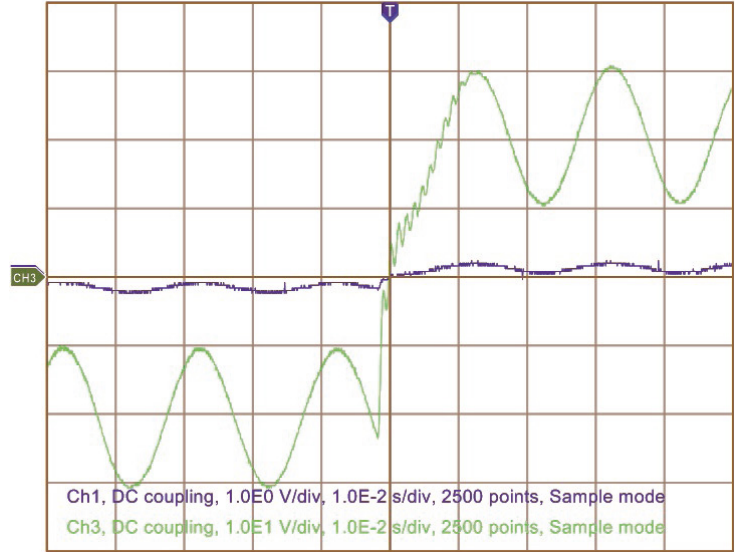

Fig. 18. Behavior of the $v c$ and $i_{R}$ signals when the reference changes from $v_{\text {ref }}=-20+10 \sin (2 \Pi * 50 \mathrm{t}) \mathrm{V}$ to $v_{\text {ref }}=20+10 \sin (2 \Pi * 50 \mathrm{t}) \mathrm{V}$ Source: Authors.

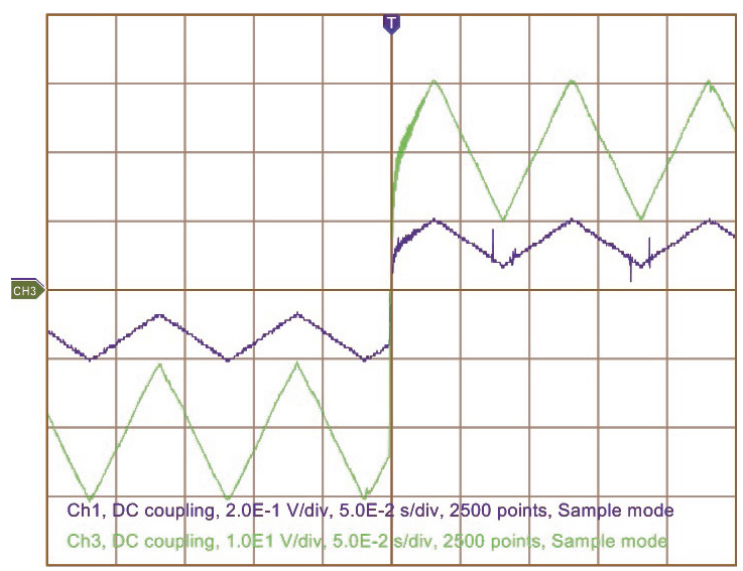

Fig. 19. Behavior of $v c$ and $i_{R}$ signals when $v_{\text {ref }}$ changes and the signal has a triangle waveform with offset Source: Authors.

Figs. 17-19 show the behavior of the output voltage and the current in the load $i_{R}$ according to the changes in the reference signal. The output signal is composed of a direct current (DC) signal and an alternating current (AC) signal. Fig. 17 shows the change of the output signal when $v_{r e f}=10 \sin (2 \Pi * 50 \mathrm{t})$ $\mathrm{V}$ is changed to $v_{\text {ref }}=20+10 \sin (2 \pi * 50 \mathrm{t}) \mathrm{V}$.

Fig. 18 shows the behavior of the output signal when $v_{\text {ref }}=-20+10 \sin (2 \pi * 50 \mathrm{t}) \mathrm{V}$ is changed to $v_{\text {ref }}=20+10 \sin (2 \pi * 50 \mathrm{t}) \mathrm{V}$.

Fig. 19 shows the behavior of the output signal when the triangle waveform with voltage magnitude of $10 \mathrm{~V}$, offset of $-20 \mathrm{~V}$, and frequency of $10 \mathrm{~Hz}$ is changed to a signal with a triangle waveform with a voltage magnitude of $10 \mathrm{~V}$, an offset of $+20 \mathrm{~V}$, and frequency of $10 \mathrm{~Hz}$. From these results, it is observed that the ZAD and FPIC techniques adapt quickly to the changes produced in the waveform, magnitude, and frequency of the reference signal. 


\section{Behavior of the buck converter with load changes}

Figs. 20-22 show the behavior of the buck converter controlled by ZAD and FPIC (with $K_{s}=5$ and $\mathrm{N}=1$ ), following the reference signal $v_{\text {ref }}=20 \sin (2 \pi * 20 \mathrm{t}) \mathrm{V}$. These figures show the behavior of the output voltage (upper part) and the current of the load $i_{R}$ (lower part) when the load of $R=151.3 \Omega$ is connected and disconnected.

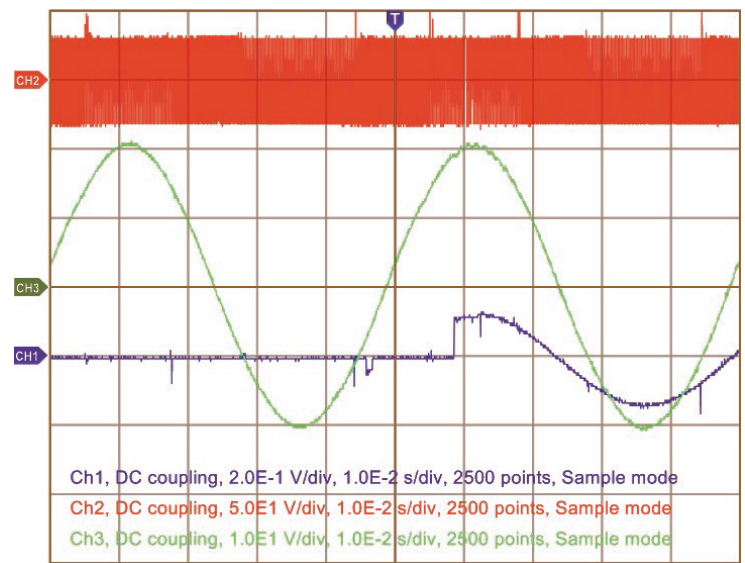

Fig. 20. Behavior of $v_{C}$ and $i_{R}$ signals when the initial resistance changes from open circuit to a resistance of $R=151.3 \Omega$ Source: Authors.

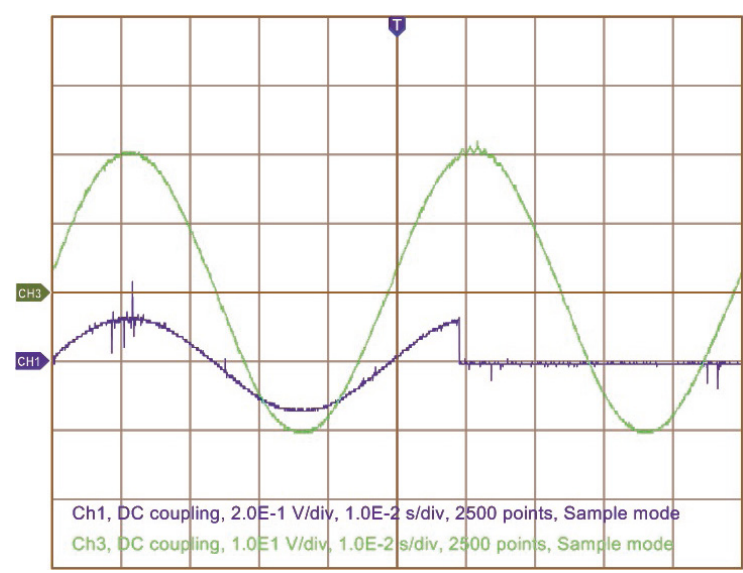

Fig. 21. Behavior of $v_{C}$ and $i R$ with a change from $R=151.3 \Omega$ to an open circuit $(R \rightarrow \infty)$ Source: Authors.

Figs. 23 and 24 show the behavior of the buck converter controlled by ZAD and FPIC (with $K_{S}=5$ and $=1$ ) when the load $R=256.3 \Omega$ is changed to $R=151.3 \Omega$. In these figures, the controlled variable $\left(v_{C}\right)$ does not suffer alteration, whereas the current in the load $i_{R}$ changes with perturbations in the load.

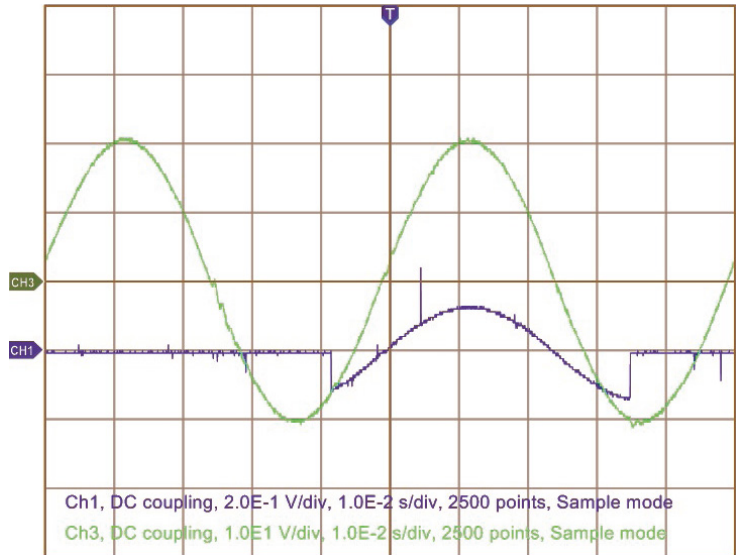

Fig. 22. Behavior of $v_{C}$ and iR with a change from $R=151.3 \Omega$ to an open circuit $(R \rightarrow \infty)$ Source: Authors.

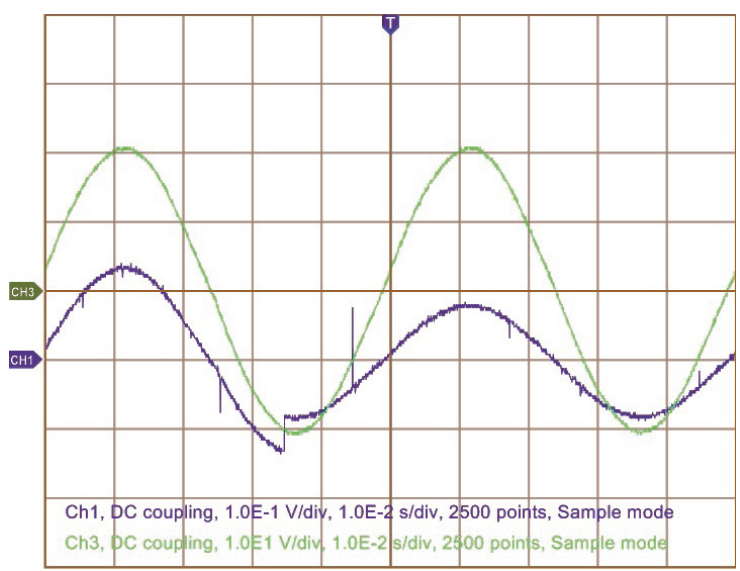

Fig. 23. Behavior of $v_{C}$ and $i_{R}$ with a change from $R=151.3 \Omega$ to $R=256.3 \Omega$ Source: Authors.

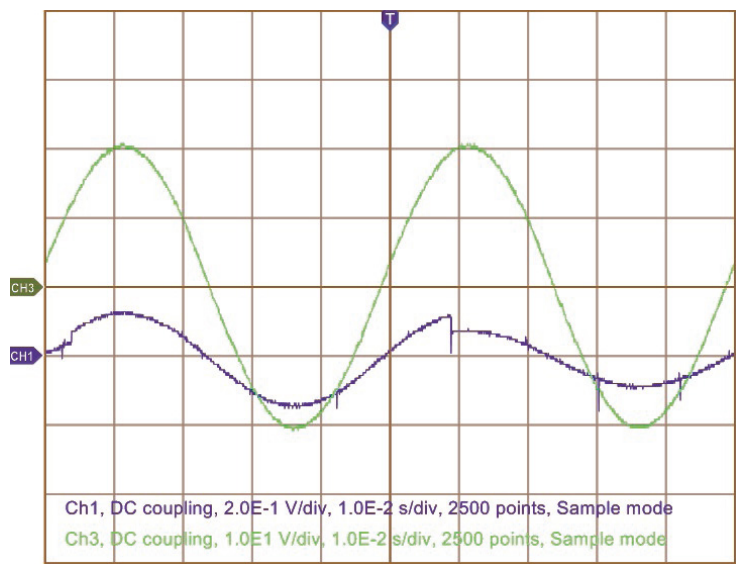

Fig. 24. Behavior of $v_{C}$ and $i_{R}$ with a change from $R=151.3 \Omega$ to $R=256.3 \Omega$ Source: Authors. 


\section{CONCLUSIONS}

This paper presented an evaluation of the response in alternating current of the buck converter with zero average dynamics (ZAD) and fixed point inducting control (FPIC). The test was based on measuring the dynamic behavior of the output voltage, current, and power according to changes in the controller. The results show that the controller allows good stability against different variations in the system and that it regulates well the output voltage of the circuit. The ZAD and FPIC techniques adapt quickly to the changes produced in the waveform, magnitude, and frequency of the reference signal.

The converter has limitations to follow high AC frequency signals due to the frequency commutation being $5 \mathrm{kHz}$. For that reason, an AC signal in the circuit with a higher frequency is required. In addition, the commutation process has to operate with a higher switching speed, which implies changes in the design of the converters such as the LC filter. It could be necessary to change optocouplers in the MOSFETs by using a higher switching speed and a faster controller such as an FPGA. Signal shielding must be considered in the circuit to avoid electromagnetic compatibility problems that distort the signals.

In this investigation, the ZAD control technique is used in conjunction with the FPIC technique. This is due to the fact that experimentally, with the use of the DSP and how it is mandatory to synchronize the sample with the output to have PWMC, there are delays in the control signal due to the time necessary to execute the closed loop. With the advantage that FPIC has of stabilizing chaotic systems, it was possible to control this system with these included delays.

\section{Acknowledgements}

This work was supported by the Universidad Nacional de Colombia, Sede Medellín under the projects HERMES-34671 and HERMES-36911. The authors thank the School of Physics and the Department of Electrical Engineering and Automation for the valuable support to conduct this research.

\section{REFERENCES}

[1] N. Mohan, Power Electronics: A First Course. Hoboken, New Jersey: John Wiley \& Sons, 2011, pp. 38-62.

[2] A. Ospino-Castro, "Análisis del potencial energético solar en la Región Caribe para el diseño de un sistema fotovoltaico," INGECUC, vol. 6, no. 6, pp. 95-102, 2010.

[3] P. A. Andrade, J. L. Morejon and E. M. Inga, "Cobertura Máxima de Redes de Sensores Inalámbricos para un Sistema de Gestión de Energía en Hogares Inteligentes. Maximum Coverage of Wireless Sensor Networks for an Energy Management System in Smart Homes," INGECUC, vol. 12, no. 2, pp. 68-78, 2016. https://doi.org/10.17981/ingecuc.12.2.2016.07

[4] D. W. Hart, Electrónica de potencia, Madrid: Prentice HallPearson Educación, 2001.
[5] N. Mohan, Advanced Electric Drives: Analysis, Control, and Modeling Using MATLAB / Simulink. John Wiley \& Sons, 2014, 208 p. https://doi.org/10.1002/9781118910962

[6] M. Rashid, Power Electronics Handbook, Third Edition, Butterworth-Heinemann, 2010, 1362 p., p. 249-264.

[7] J. L. Strack, J. A. Suárez, G. F. Di Mauro and S. B. Jacob, "Impacto de la iluminación residencial eficiente en la calidad de la energía de una red de distribución" INGE CUC, vol. 10, no. 2, pp. 9-19, Dec. 2014

[8] E. Fossas, R. Griñó and D. Biel, "Quasi-Sliding control based on pulse width modulation, zero averaged dynamics and the L2 norm," Advances in Variable Structure Systems - 6th IEEE International Workshop on Variable Structure Systems, pp. 335-344, 2000. https://doi. org/10.1142/9789812792082_0031

[9] R. R. Ramos, D. Biel, E. Fossas and F. Guinjoan, "A fixed-frequency quasi-sliding control algorithm: application to power inverters design by means of FPGA implementation," IEEE Trans. Power Electron., vol. 18, no. 1, pp. 344-355, Jan. 2003. https://doi.org/10.1109/TPEL.2002.807164

[10] F. Angulo, G. Olivar and M. di Bernardo, "Two-Parameter Discontinuity-Induced Bifurcation Curves in a ZADStrategy-Controlled DC-DC Buck Converter", IEEE Transactions on Circuits and Systems, vol 55, no. 08, pp. 2392-2401, 2008. ISBN: 1549-8328. https://doi.org/10.1109/ TCSI.2008.918226

[11] F. E. Hoyos, N. Toro and Y. A. Garcés, "Adaptive Control for Buck Power Converter Using Fixed Point Inducting Control and Zero Average Dynamics Strategies," Int. J. Bifurcation. Chaos, vol. 25, no. 4, pp. 1550049-150061, Apr. 2015. https:// doi.org/10.1142/S0218127415500492

[12] J. Taborda, D. Burbano and F. Angulo, "Quantization Effects on Period Doubling Route to Chaos in a ZAD-Controlled Buck Converter", Mathematical Problems in Engineering, vol 2012, pp. 1-19, 2012. https://doi.org/10.1155/2012/526394

[13] A. EL Aroudi, F. Angulo, G. Olivar, B. G. M. Robert and M. Feki, "Stabilizing a two-cell dc-dc buck converter by fixed point induced control," International Journal of Bifurcation and Chaos, 2009, vol 19, no. 06, pp. 2043-2057, 2009. https:// doi.org/10.1142/S0218127409023895

[14] J. Muñoz, G. Osorio, and F. Angulo, "Boost converter control with ZAD for power factor correction based on FPGA", Workshop on, Power Electronics and Power Quality Applications (PEPQA), pp. 1-5, 2013. https://doi.org/10.1109/PEPQA.2013.6614942

[15] F. E. Hoyos, D. Burbano, F. Angulo, G. Olivar, N. Toro and J. A. Taborda, "Effects of quantization, delay and internal resistances in digitally ZAD-controlled buck converter," Int. J. Bifurcation and Chaos, vol. 22, no. 10, pp. 1250245, Oct. 2012. https://doi.org/10.1142/S0218127412502458

[16] P. Deivasundari, G. Uma and S. Ashita, "Chaotic dynamics of a zero average dynamics controlled DC-DC Ćuk converter," IET Power Electron., vol. 7, no. 2, pp. 289-298, Feb. 2014. https://doi.org/10.1049/iet-pel.2012.0737

[17] F. Angulo, G. Olivar, J. Taborda, and F.E Hoyos, "Nonsmooth dynamics and FPIC chaos control in a DC-DC ZAD-strategy power converter," in ENOC, pp. 1-6, 2008.

[18] F. Angulo, "Análisis de la dinámica de convertidores electrónicos de potencia usando PWM basado en promediado cero de la dinámica del error (ZAD)," Universidad Politécnica de Cataluña, 2004.

[19] F. Angulo, J. E. Burgos, and G. Olivar, "Chaos stabilization with TDAS and FPIC in a buck converter controlled by lateral PWM and ZAD," in 2007 Mediterranean Conference on Control \& Automation, pp. 1-6, Jun. 2007. https://doi. org/10.1109/MED.2007.4433846

[20] J. A. Taborda, S. Santini, M. di Bernardo, and F. Angulo, "Active Chaos Control of a Cam-Follower Impacting System using FPIC Technique," IFAC Proc. vol. 42, no. 7, pp. 327-332, 2009. https://doi.org/10.3182/20090622-3-UK-3004.00061

[21] F. E. Hoyos Velasco, C. Younes Velosa, and E. A. Cano Plata, "Técnicas de filtrado de IEM en convertidores electrónicos de potencia," Ing. e Investig., vol. 30, no. 2, pp. 168-177, 2010. 
Fredy E. Hoyos received a B.S. degree in electrical engineering in 2005, an M.S. in industrial automation in 2008, and a Ph.D. in automation in 2012, all from Universidad Nacional de Colombia, Manizales, Colombia. He is currently a full professor in the School of Physics in Universidad Nacional de Colombia-Medellín. His research interests include nonlinear dynamics and nonlinear control with applications to power converters and electric machines. https://orcid.org/0000-0001-8766-5192

John E. Candelo received his B.S. degree in electrical engineering in 2002 and his Ph.D. in engineering with an emphasis in electrical engineering in 2009 from Universidad del Valle, Cali - Colombia. His employment experiences include the Empresa de Energía del Pacífico EPSA, Universidad del Norte, and Universidad Nacional de Colombia - Sede Medellín. He is now an Assistant Professor at Universidad Nacional de Colombia - Sede Medellín, Colombia. His research interests include engineering education, planning, operation and control of power systems, artificial intelligence, and smart grids. http:// orcid.org/0000-0002-9784-9494

Jorge I. Silva-Ortega received a M.Sc. degree in electrical engineering from Universidad del Norte in Barranquilla, Colombia. He is now a Ph.D. student at Universidad Pontificia Bolivariana (UPB) en Medellín, Colombia. Since 2011, he has been an active member of the GIOPEN research group at Universidad de la Costa en Barranquilla and he is associate researcher in Colciencias. https://orcid. org/0000-0002-7813-0142 